\title{
O ENSINO DE PSICOLOGIA NO ENSINO MÉDIO, PROFISSIONAL E NA FORMAÇÃO DE PROFESSORES: EM BUSCA DE UMA UNIDADE
}

\author{
TEACHING OF PSYCHOLOGY SECONDARY \\ EDUCATION, PROFESSIONAL TRAINING AND \\ TEACHER EDUCATION: IN SEARCH OF UNITY
}

\author{
Juliano Del Gobo* \\ Maurício Wisniewski ${ }^{* *}$
}

\begin{abstract}
RESUMO
O ensino da Psicologia integrando currículo de outros cursos que não os de formação de psicólogos, tem uma trajetória de descontinuidade entre momentos de inclusão e outros de exclusão. Podem ser condições históricas que dificultam a legitimidade da Psicologia enquanto área do conhecimento capaz de contribuir com essas formações, mas também podem apontar para possibilidades de atuação nesta área. $\mathrm{O}$ objetivo deste artigo foi apresentar a situação atual do ensino de Psicologia nos cursos de Ensino Médio, profissionalizante e nos cursos de formação de professores em licenciaturas. Teve-se como metodologia a pesquisa bibliográfica. A análise histórica permitiu a observação dos movimentos político, social e principalmente, da face epistemológica que envolve a construção da Psicologia como ciência e profissão. Pode-se, apontar algumas dificuldades para a consolidação da Psicologia no ensino em outras formações, entre elas as dificuldades da estruturação da Psicologia enquanto ciência, como a diversidade de objetos e métodos, o distanciamento entre teoria e prática do profissional com o contexto social. Contudo, à Psicologia se reserva um papel importante no plano da valorização da subjetividade e da valorização da diferença na sociedade moderna, um campo de atuação fértil, mas que ainda precisa de uma unidade mais solidificada e organizada, além de um posicionamento político-ideológico bem demarcado.
\end{abstract}

Palavras-chave: Psicologia. Ensino. Formação de professores. Subjetividade

\begin{abstract}
The teaching of Psychology in the curriculum of courses other than those that prepare psychologists has a trajectory of inclusion and exclusion. Historical conditions can account for the difficulties in the legitimation of Psychology as a field of knowledge that can contribute to these professional courses, but may also point to possibilities for action in this area. This article aims to present the current status of Psychology teaching in high school courses, in vocational education and higher education, specifically in teacher training courses. The study took the
\end{abstract}

\footnotetext{
"Psicólogo, formado pela Universidade Federal do Paraná (UFPR), especialista em Metodologia de Ensino Superior. E-mail: <jdg.psicologia@gmail.com>

* Psicólogo, formado pela Universidade Federal do Paraná (UFPR) mestre em Educação pela Universidade Estadual de Ponta Grossa; doutorando em Educação pela Universidade Federal do Paraná. E-mail: <mauriciowis@gmail.com>.
} 
form of a bibliographical research. Historical analysis allowed the observation of the political and social movements and, most importantly, the epistemological view that involves the construction of Psychology as a science. As a consequence it is possible to point out some difficulties for the consolidation of Psychology in other professional training courses. These obstacles relate to the difficulty of structuring Psychology as a science due the diversity of objects and methods, the gap between theoretical knowledge and professional practice and the social context. Nevertheless, Psychology assigns itself an important role in terms of appreciation of subjectivity and in valuing differences in modern society, a fertile field of endeavor, but it still needs a more solidified and organized unit, and a wellestablished political-ideological positioning.

Keywords: Psychology. Teaching. Teacher education. Subjectivity.

\section{Introdução}

A discussão a respeito da Psicologia, enquanto disciplina ou enquanto campo do saber que compõe com outros saberes a área da educação brasileira, não é recente. Segundo Massimi (1993), os conhecimentos psicológicos já estão presentes em teses da Faculdade de Medicina e de Direito do início do século XIX, e, a partir daí, também passam a compor currículos da formação secundária de formação profissionalizante, em especial aqueles voltados ao magistério e ao ensino de modo geral, à saúde, à comunicação, administração e serviços de atendimento em geral (MORENO, 1996). No nível superior, o ensino de Psicologia para curso de não psicólogos, esteve e está presente na área da Educação, nos cursos de Pedagogia e de licenciaturas, na área da Saúde em diversos cursos, no curso de Direito e hoje, tende a ampliar sua inserção em muitos outros domínios com sua consolidação no campo educativo. Além disso, no presente momento, os órgãos representativos da Psicologia têm buscado um constante diálogo com as sociedades civil e política, visando à reinserção da Psicologia como disciplina obrigatória no Ensino Médio (AZZI; \& SOLIGO, 2007).

Nesse cenário em que o ensino de Psicologia interessa não somente à formação de psicólogos, mas passa a contribuir com a formação de outros profissionais e também na constituição de humanidades, como é o caso da sua inclusão no Ensino Médio, a necessidade de estudos na área e de meios que fortaleçam e legitimem sua prática são de extrema importância. Nessa direção, o presente estudo pretende lançar um olhar questionador sobre as dificuldades e possibilidades que envolvem tal prática e despertar o interesse de mais pesquisas, que levem em conta o contexto social e as necessidades de cada porta que se abre para as contribuições da Psicologia.

Este artigo pretende apresentar a situação atual do ensino de Psicologia, para não psicólogos, englobando o Ensino Médio, o Ensino Profissionalizante e o Ensino Superior, especificamente, na formação de professores em licenciaturas. ${ }^{1}$ Analisar historicamente a evolução desses ensinos e refletir a respeito da formação dos profissionais psicólogos para que possam desenvolver suas atividades de forma coerente, seguindo não os mesmo pressupostos teóricos, mas sim os éticos, para que a Psicologia possa contribuir efetivamente com as questões da educação e de algumas profissões com que vem a dialogar. Pergunta de pesquisa: como vem se organizando, ao longo dos anos, o ensino da Psicologia para não psicólogos nos níveis médio, profissional e nas licenciaturas? Que contribuições têm o ensinar Psicologia em comum nos níveis médio, profissional e nas licenciaturas?

\section{A Psicologia no Ensino Médio}

Para Azzi e Soligo (2000), a Psicologia na história do Ensino Médio do país teve uma trajetória marcada, ao mesmo tempo, por irregularidade e constância, referindo-se às oscilações que esta disciplina teve, no que se refere a fazer parte do currículo

\footnotetext{
${ }^{1}$ Conforme a Lei n. 9.394, de 20 de dezembro de 1996.
} 
regular do Ensino Médio e da sua presença constante como disciplina no Ensino Profissionalizante, principalmente na formação de professores e na área da saúde. Diversos autores (AZZI; SOLIGO, 2007; LEITE, 2007; GUERRA, 1998) afirmam que a Lei de Diretrizes e Bases da Educação Nacional LDBEN de 1971, engendrada no período da ditadura militar, pôs fim à presença das Ciências Humanas no Ensino Médio regular, privilegiando uma formação tecnicista, sendo a disciplina de Psicologia retirada do Ensino Médio regular, até então, definitivamente.

$\mathrm{O}$ processo de mudança desencadeado com o fim da ditadura militar trouxe a necessidade de debates visando profundas mudanças no sistema educativo brasileiro, culminando na Constituição de 1988 e na nova LDB de 1996, na qual se reconhece a importância das Ciências Humanas na formação dos adolescentes e jovens. Há, então, a incorporação das disciplinas de Filosofia e Sociologia no currículo do Ensino Médio, porém a Psicologia, mesmo tendo reconhecida sua importância como conteúdo transversal, não é incorporada. No presente momento, tem-se buscado pelos órgãos representativos da Psicologia um constante diálogo com a sociedade civil e política visando à reinserção da Psicologia como disciplina obrigatória no Ensino Médio.

Leite (2007), analisando os movimentos que ocorreram em prol da Psicologia no Ensino Médio a partir dos anos 1980, demonstra de um lado dois movimentos. $\mathrm{O}$ primeiro seria a exigência da Secretaria de Educação em analisar criticamente a efetiva contribuição da Psicologia na promoção do pensamento crítico e da transformação social. E outro, na dificuldade da Psicologia em comprovar sua contribuição efetiva. $O$ autor nota que algumas dificuldades remetem a antigos problemas da Psicologia, como: demonstrar conteúdos que superassem modelos tradicionais, biologizantes e naturalizantes dos fenômenos psicológicos; os conteúdos deveriam permitir uma crítica ao sistema ideológico dominante, principalmente no que se refere ao individualismo, exigência que remetia à tendência da Psicologia em responsabilizar as mazelas sociais e individuais ao nível interno, excluindo da análise as questões sociais e institucionais; e, por último, que os conteúdos deveriam respeitar a diversidade teórica da Psicologia.
Analisando o contexto atual da Psicologia, o autor considera que a questão fundamental continua sendo: qual a contribuição que a Psicologia, enquanto ciência e profissão, tem a oferecer ao processo educacional dos jovens numa perspectiva de formação de cidadãos críticos e transformadores? Para o autor, o profissional psicólogo que se interesse pela docência deve estar, antes de tudo, comprometido com a reconstrução de um sistema educacional como um espaço de construção de consciência crítica e da cidadania transformadora.

\section{A Psicologia no ensino profissionalizante}

Como aponta Pires (2009, p.117) "ser professor é poder alargar os sentidos dados à própria organização do conhecimento e ao objeto do ensinar" e colocar em análise crítica e reflexiva o porquê da escolha de alguns conhecimentos em detrimento de outros. Ser professor, neste olhar, é visar a integralidade do aluno com seu objeto, retirando-o de uma posição marcada pelo tecnicismo. Posicionamento que se torna fundamental quanto pensado no Ensino Profissionalizante, pois segundo a autora, mesmo com o avanço nos discursos acadêmicos e de gestão, o que marca o ensino técnico no Brasil ainda é a lógica tecnicista com ênfase no saber-fazer, em detrimento do saber de si, da vida.

Para o profissional psicólogo que vem a atuar no ensino técnico da saúde, reconhecidamente marcado pelo modelo médico e pelo empobrecimento subjetivo do sujeito-paciente oculto, ocupado até então por um saber técnico que observa um paciente-objeto, seu posicionamento se faz urgente. Nas palavras de Guatterri e Rolnik (2000, p.29),

[...]todos aqueles, enfim, que a profissão se interessar pelo discurso do outro. Eles se encontram em uma encruzilhada política e micropolítica fundamental. Ou vão fazer o jogo dessa reprodução de modelos que não permitem criar saídas para os processos de singularização, ou ao contrário, vão estar trabalhando para o funcionamento desses processos na medida de suas possibilidades e dos agenciamentos que consigam por para funcionar. Isso quer dizer que não há objetividade científica alguma nesse campo, nem uma suposta neutralidade nessa relação. 
Para Pires (2009) o ensino da Psicologia inserido na Educação Profissional precisa contribuir significativamente na construção de um trabalhador que se coloque como ator e autor na sua prática, e que o diferencie, que o engaje em um projeto maior, um projeto político. O professor da Educação Profissional não pode então, buscar formar somente o aspecto instrumental, metodológico, mas proporcionar um aparato conceitual crítico, capaz de dar conta da análise reflexiva da realidade concreta.

Com esse posicionamento a autora em uma pesquisa que resultou em sua dissertação de mestrado questiona como os professores de Psicologia, envolvidos com o Ensino Profissionalizante na área da saúde, entendem sua contribuição neste ensino. Diante do modelo médico e do empobrecimento subjetivo, realizou uma pesquisa partindo do pressuposto de que no ensino não existe neutralidade, pelo contrário - o compromisso político ideológico exige escolhas conscientes que resultarão em produção concreta na realidade. Dessa forma a autora refletindo a partir de Neto (2000), aponta que o docente mais do que ligado ao saber, deve estar consciente dos compromissos que tais saberes têm com a realidade concreta e alinhado a processos pedagógicos capazes de promover os princípios da atividade democrática, que neste caso, são os princípios do Sistema Único de Saúde, possa ver na educação uma prática social significativa.

\section{A psicologia na formação de professores}

Se há uma área em que a Psicologia foi sempre reconhecida como uma disciplina importante é a formação docente. Ocupando seu espaço enquanto matéria pedagógica obrigatória, a Psicologia foi ao longo dos anos construindo e transformando sua prática relacionada às questões educacionais. Ao longo da sua história esteve sempre presente no processo de formação docente enquanto uma área de conhecimento que procura oferecer subsídios para as práticas educativas, prioritariamente oferecendo subsídio teórico sobre os processos de desenvolvimento e de aprendizagem (GUERRA, 2000).

Agrupados na chamada Psicologia da Educação ou Psicologia Educacional, estes conhecimentos seguiram os mesmos passos que a Psicologia científica na constituição do seu campo se saber.
Rompeu com a filosofia e buscou amelhoria das práticas educativas e principalmente da escolarização adquirindo explicações no método experimental das ciências físicas e naturais (COLL, 2000). Como aponta Azzi (texto publicado pela ABEPSI) o início da Psicologia da Educação no século XIX foi marcado por estudos e parâmetros sobre normalidade, desenvolvimento e aprendizagem aceitáveis, visando uma universalização do ensino escolar e a construção de mentalidades que se adequassem a uma ordem do progresso tecnológico. Esta postura inicial que rende ainda a esta disciplina severas críticas, principalmente ao modelo de sujeitos naturalizados e universalizados, hoje dá lugar ao reconhecimento da necessidade de compreender as dimensões psicológicas e psicossociais dos homens.

Coll (1999) afirma que no percurso da Psicologia da educação, pela década de 1960, houve um deslocamento dos estudos de aprendizagem para o interesse pela instrução, vindo assim a ocupar um papel privilegiado nas pesquisas educativas, na formação docente e nos serviços e Psicologia escolar. Com tal abertura os conhecimentos psicológicos foram bastante valorizados pela educação, porém sua utilização foi feita, segundo Guerra (2000), de maneira aleatória e unidirecional, desconsiderando a diversidade teórica da Psicologia enquanto ciência. No campo epistemológico como afirma Japiassu (1983), a Psicologia está situada em meio há diversidade de domínios e de métodos, e se reparte em várias tendências ou escolas em que a opção por uma delas se dá pela posição ideológica ou filosófica do profissional.

Tal questão é sentida pelo campo da Psicologia da Educação, em que algumas correntes historicamente se destacaram. Desinteressante para este artigo aprofundar este assunto, mas pode ter valia ao menos citá-las: a corrente inatista-maturacionista que imputava maior importância aos fatores hereditários que as demais no desenvolvimento cognitivo; a corrente behaviorista que mesmo não tendo desconsiderado os eventos internos, deu maior ênfase à questão da aprendizagem enfatizando o ambiente externo e os mecanismos de condicionamento; a corrente piagetiana envolvida principalmente com os conceitos de assimilação, acomodação e adaptação envolvidos num processo de maior, o equilibração, onde parte-se por etapas, a partir de estruturas 
cognitivas mais simples para as mais complexas (AZZI, 2000).

Além destas, destaca-se ainda a corrente soviética da Psicologia histórico-cultural de Vygotsky (1997), que pensa o desenvolvimento como processo de humanização, considerando que a criança já nasce inserida num contexto sócio-cultural e vai, a partir da interação com o meio e, principalmente com o outro, internalizando as produções humanas acumuladas ao longo da história da humanidade. Essa abordagem, segundo Van der Veer e Valsiner (1996 apud AZZI, 2000), segue dois aspectos: primeiro, o predominantemente natural de maturação e crescimento; e, posteriormente o de um processo cultural que depende do desenvolvimento do processo de humanização, do domínio da linguagem e dos instrumentos culturais. Para Bock (1999) a Psicologia é caracterizada pela diversidade de objetos de estudo, fato que se justifica pela recente estruturação enquanto área do conhecimento científico e pela variedade de concepções de homem existentes na sociedade. Para a autora, a concepção de homem que acompanha o pesquisador influencia sua abordagem na prática em Psicologia, o que não exclui a área de ensino. Frente a esta particularidade da ciência ou ciências psicológicas, em determinados momentos históricos uma dessas abordagens superou a outra, porém continuam ainda dividindo o mesmo espaço temporal proporcionando debates teóricos e epistemológicos que com eles levam o desenvolvimento da ciência educacional.

Por outro lado, a repercussão da construção do conhecimento que a Psicologia promove no ensino das licenciaturas é apontada em pesquisa realizada por Larocca (1999) a partir da percepção que alunos e professores do ensino público e privado têm da experiência em sala de aula e com o enfrentamento das primeiras experiências docentes. Em sua pesquisa aparecem quatro problemáticas do ensino de Psicologia: a desarticulação entre a prática, formação e realidade; a insuficiência de carga horária; o trabalho dos formadores na organização e condução dos estudos e no que se refere às atitudes profissionais e por final a ausência de preocupação em vincular a Psicologia da Educação com a área de conhecimento específica do curso.

\section{Discussão}

A discussão deste artigo pretende buscar nos caminhos percorridos pelo ensino de Psicologia no Ensino Médio, Profissionalizante e formação de professores nas licenciaturas, temas em comum no ensino de Psicologia fora dos cursos de Psicologia. Também visa identificar a presença de dificuldades em comum, como elas se apresentam e possíveis caminhos para o desenvolvimento de um ensino mais coerente e eficiente.

O Ensino Médio sempre reservou ao ensino da Psicologia um espaço de constante incerteza, levando a uma dificuldade de desenvolvimento da mesma (AZZI; SOLIGO, 2007; LEITE, 2007; GUERRA, 1998). Como essa disciplina deveria ser desenvolvida prioritariamente por profissionais habilitados nos cursos de licenciatura, o efeito das oscilações no espaço das disciplinas de Ensino Médio acarreta hoje um grande desprestígio dos cursos de Psicologia com habilitação em licenciatura, contrastando com a crescente demanda pelo ensino de Psicologia (SIMÕES, 2007).

Sendo então o Ensino Médio um campo de atuação que não chegou a se efetivar, pode-se pensar no contraste se comparado ao ensino profissionalizante, que muitas vezes ocupado por alunos de Ensino Médio, teve em sua matriz curricular a presença quase permanente da disciplina de Psicologia. Se no Ensino Médio a Psicologia deveria buscar, como afirma Leite (2007), contribuir na promoção do pensamento crítico e da transformação social, no Ensino Profissionalizante como afirma Pires (2009), de característica marcadamente tecnicista, do modelo médico-biológico quando na esfera da saúde, se resumia a formar somente o aspecto instrumental e metodológico dos profissionais, sem buscar proporcionar um aparato conceitual crítico, capaz de dar conta da análise reflexiva da realidade concreta.

Por outro lado, o ensino da Psicologia nas licenciaturas pareceu um campo de atuação muito mais legítimo, isto é, que sempre ocupou seu espaço mesmo não tendo bem claro quais seriam as contribuições efetivas na formação docente. $\mathrm{O}$ que se percebe é que ao longo dos anos esta disciplina relacionada às questões educacionais foi sendo construída e transformada. Como afirma Coll (1999) no percurso da Psicologia da educação, houve um 
deslocamento dos estudos de aprendizagem para o interesse pela instrução, vindo assim a ocupar um papel privilegiado nas pesquisas educativas, na formação docente e nos serviços e na Psicologia escolar. Contudo, esse campo, mesmo tendo o tempo e a diversidade de aplicações fundamentais para a construção de um substrato teórico significativo teve sua utilização, segundo Guerra (2000), de maneira aleatória e unidirecional, desconsiderando a diversidade teórica da Psicologia enquanto ciência.

A desconsideração da diversidade teórica da Psicologia é apontada por Leite (2007) como uma problemática levantada pela Secretaria Paulista de Educação na década de 1970 em debates acerca da inclusão da Psicologia no Ensino Médio daquele estado. Entre outras dificuldades o autor nota que algumas delas remetem a antigos problemas da Psicologia enquanto ciência, como: demonstrar conteúdos que superassem modelos tradicionais, biologizantes e naturalizantes dos fenômenos psicológicos; os conteúdos deveriam permitir a possibilidade de uma crítica ao modelo social vigente; além de que os conteúdos deveriam respeitar a diversidade teórica da Psicologia.

Retornando ao desenvolvimento da disciplina de Psicologia nos cursos de licenciatura, o que se percebeu foram tendências psicológicas revezando entre si nos debates ideológicos nas universidades, ora elegendo-se uma, ou outra tendência em detrimento de outras.

Diante deste diálogo entre os autores que estudam o ensino de Psicologia nestes três ramos distintos, são perceptíveis a fragmentação destes ensinos e a necessidade de uma estruturação que legitime tal prática e se faça reconhecer sua contribuição efetiva. Nas palavras de licenciandos e professores de licenciaturas, quatro problemáticas encontradas por Larocca (1999) apresentam caminhos a ser construídos: a desarticulação entre a prática, formação e realidade; a insuficiência de carga horária; o trabalho dos formadores na organização e condução dos estudos; e a ausência de preocupação em vincular a Psicologia com a área de conhecimento específica do curso. Estes pontos são bem significativos ao se analisar que o ensino nas licenciaturas foi o que teve mais possibilidade de evoluir.

Bock (1999) ao analisar a escola e os obstáculos que estão entre o ensino, a vida escolar e as práticas sociais conscientes, aponta que a escola está longe da realidade, ainda representa o espaço privilegiado em que as potencialidades podem se desenvolver a partir das aulas ministradas por professores capazes desta "tarefa divina", os conteúdos estão deslocados na realidade e o pensamento é operado e dirigido para o nível individual afastando-se da complexidade do ser social. Ao refletir sobre esta crítica ao modelo de escola que se tem no Brasil atualmente, percebe-se uma semelhança com a prática do ensino de Psicologia nos cursos que não Psicologia, onde a premissa do professor conduzir a disciplina guiado pelos seus próprios ideais, desfigurando a disciplina em partes, sem o compromisso de fornecer instrumentais para aqueles que ensina, é visível. No sempre válido alerta de Enriquez (2006) sobre a atual condição socioeconômica da sociedade capitalista, cujo vínculo social se desfaz continuamente e de onde cresce uma forma de violência sutil, quase imperceptível, que visa suprimir não somente o indivíduo, mas também o sentido da vida, a necessidade de se pensar a disciplina da Psicologia ancorada num plano ideológico consistente se faz urgente.

Para Pires (2009) o ser professor, é visar à integralidade do aluno com seu objeto em detrimento da lógica tecnicista com ênfase no saber-fazer, em detrimento do saber de si, do saber da vida. Em Larocca (1999) a queixa sobre o desinteresse em vincular a Psicologia com a área de conhecimento específico do curso que atende é preocupante, pois, como modelo de ensino serve muito bem, porém como disciplina emancipadora que concorre na produção de sentido em uma sociedade de consumo, pouco tem a contribuir com o desenvolvimento subjetivo. Aproximando-se deste pensamento, Pires (2009) concorda que no ensino não existe neutralidade, pelo contrário, o compromisso político ideológico exige escolhas conscientes que resultarão em produção concreta na realidade e assim, o docente mais do que ligado ao saber, deve estar consciente dos compromissos que tais saberes têm com a realidade concreta.

\section{Considerações finais}

Nem sempre é fácil apontar as fragilidades das práticas do campo de saber em que se atua, porém 
muitas vezes isso se faz necessário para construir outras mais consistentes e embasadas. Na tentativa de demarcar a condição atual do ensino de Psicologia para não psicólogos, abordamos três práticas: no Ensino Profissionalizante, no Ensino Médio e na formação de professores, de modo que as diferentes experiências nos conduzissem às dificuldades e possibilidades do ensino da Psicologia fora dos cursos de formação de psicólogos.

No que se refere aos objetivos almejados, pudemos reunir neste trabalho uma série de apontamentos, não somente no quadro atual, mas também das condições históricas e políticas que colaboraram para este estado das coisas no ensino, como foi o caso do advento da ditadura militar e da reformulação das diretrizes dos currículos de Ensino Médio e Profissionalizante. Como fruto de sua história, o ensino de Psicologia fora dos cursos de formação, também esbarra na fragmentação da constituição teórica e epistemológica da ciência psicológica que, reconhecendo a possibilidade de seus vários objetos e métodos, permite um ensino dirigido a fundamentações diversas. Esse aspecto se torna mais perturbador quando do reconhecimento da ausência de um entendimento sobre tal diversidade pelas instituições de ensino, que acabam deixando ao posicionamento ideológico dos profissionais-professores a escolha pelo referencial, que queremos destacar, pode ser bastante ética e abrangente ou, infelizmente irresponsável.

Por outro lado, este artigo vem demonstrar que, como uma área de conhecimento reconhecidamente implicada com os processos de subjetivação, a Psicologia, pode sim contribuir na construção de sujeitos conscientes, críticos e compromissados na construção de uma sociedade mais saudável, na qual o direito àdiferença é respeitado e com ele, há a possibilidade de reconstruir as instituições e novos modos de vida na sociedade brasileira. Pode, além de instrumentalizar profissionais com conhecimentos técnicos, propiciar um conhecimento sobre si, sobre as condições históricas que reconhecem a necessidade de sua prática. Ao professor pode dar-lhes conhecimentos teóricos sobre educação como se vem fazendo de forma contínua, mas pode também dar-lhe a sensibilidade de situar-se entre a diversidade que o micro-espaço social engloba, fazendo intervenções oportunas que terão consequência no nível educacional.
Porém, tais efeitos dependem de maior organização da Psicologia enquanto ciência e profissão, atenta às particularidades brasileiras, com suas diferenças, descobrindo os brasileiros, com suas potencialidades e seus problemas histórico-culturais.

A nova configuração da Psicologia como profissão no Brasil, parece ir ao encontro de tal chamado. $\mathrm{Na}$ área de ensino encontramos a Associação Brasileira de Ensino de Psicologia (ABEPSI) que vem discutindo que formação de psicólogos a sociedade brasileira quer e precisa; e qual o papel da Psicologia no ensino para não psicólogos. $\mathrm{Na}$ área das políticas públicas temos o Centro de Referência Técnica em Psicologia e Políticas Públicas (CREPOP) propondo discussões que levam sempre ao protagonismo da sociedade civil na construção das políticas, além da formulação de documentos que embasem, num marco teórico abrangente, a prática dos profissionais psicólogos em diversas áreas de atuação. Um caminho promissor e que não está isolado, pois em intercâmbio cada vez maior com outros países da América Latina, e vem construindo marcos teórico-práticos comuns.

\section{Referências}

AZZI, G. R.; BATISTA, S. H; SADALLA, A. F. A. Formação de professores: discutindo o ensino da Psicologia. São Paulo: Alínea, 2000.

AZZI, G. R.; SADALLA, A. F. A. Psicologia e Formação Docente: desafios e conversas. São Paulo: Casa do Psicólogo, 2003.

BOCK, A.M.B. Psicologias: Uma Introdução ao Estudo de Psicologia. São Paulo: Saraiva, 1999.

BRASIL. Lei n. 9.394/96. Dispõe sobre a Lei de Diretrizes e Bases da Educação. Brasília: 24 de dezembro de 1996.

COLL, C. Psicologia do Ensino. Porto Alegre: Artes Médicas, 2000.

GUATTARI, F. ; ROLNIK, S. Micropolítica: cartografias do desejo. Petrópolis: Vozes, 2000.

GUERRA, C.T. Conhecimentos Psicológico e Formação de Professores. In AZZI, R.G.; BATISTA S.H.S; SADALLA, A.M.F.A. (Orgs). Formação de Professores: discutindo o ensino de Psicologia. São Paulo: Ed. Alínea, 1998.

GUIAR, W.M.J.; BOCK, A.M.B. Psicologia da Educação: em busca de uma leitura crítica e de uma atuação compromissada. In: A Perspectiva Sócio-Histórica na Formação em Psicologia. Vozes, 2003. 
JAPIASSU, H. A Psicologia dos psicólogos. Rio de Janeiro: Imago, 1983.

LAROCCA, P. Psicologia na formação docente. Campinas, SP: Alínea, 1999.

LEITE, S.A.S. Psicologia no ensino médio: desafios e perspectivas. Temas em Psicologia, v. 15, n.1, p. 11-21, 2007.

MASSETO.M.T. Competência pedagógica do professor universitário. São Paulo: Summus, 2003.

MASSIMI, M. Projetos de Lei Prevendo a Inserção da Psicologia nos Currículos do Ensino Superior e Secundário no Brasil no Século XIX. Psicologia: Teoria e Pesquisa. Brasília: 1993, 9, (2): p.261-269.

MORENO, M.P. Ensino de Psicologia no $2^{\circ}$ grau segundo professores (dissertação de mestrado). Instituto de Psicologia. PUC-Campinas, 1996.

NETO, F. Ser professor: necessidade de formação profissional específica. Formação, v. 2, n. 4, 2002.

PIRES, F.H. O ensino da Psicologia na formação profissional: (des) compromissos docentes com a saúde. Faculdade de Educação da Universidade Federal de Porto Alegre (dissertação de mestrado). Porto Alegre: 2009.

SOLIGO, A.F. Contribuições da Psicologia Social para a formação do professor: representações sociais e atitudes. In AZZI, R.G.; SADALLA, A.M.F.A. (Orgs). Psicologia e Formação Docente: desafios e Conversas. São Paulo: Casa do Psicólogo, 2002.

VYGOTSKY, L. S. A formação social da mente. São Paulo: Martins Fontes, 1997.

Data de submissão: setembro de 2012

Data de aprovação: abril de 2013 